\title{
RECALQUE, REJEIÇÃO, DENEGAÇÃO: MODULAÇÕES SUBJETIVAS DO QUERER, DO CRER E DO SABER*
}

Lina Schlachter e Waldir Beividas

Lina Schlachter
Mestre em Teoria
Psicanalítica pela
UFRJ. Doutora em
Psicologia Clínica
pela University
of Tennessee.
Psicóloga clínica em
Fortaleza, Ceará.
Waldir Beividas
Doutor em
Semiótica e
Linguística pela
USP. Pós-doutorado
pela École des
Hautes Études en
Sciences Sociales.
Professor da
Pós-graduação
em Linguística e
Semiótica da USP.

Lina Schlachter

Mestre em Teoria

UFRJ. Doutora em

Psicologia Clínica

pela University

of Tennessee.

Psicóloga clínica em

Waldir Beividas

Doutor em

Linguística pela

USP. Pós-doutorado

Hautes Études en

Sciences Sociales

Professor da

Pós-graduação

Semiótica da USP.
RESUMO: Retomam-se três conceitos freudianos - a Verdrängung, a Verwerfung e a Verleugnung - , discute-se as dificuldades de seu entendimento frente às traduções disponíveis em português, com base numa análise semântica dos originais em alemão. Em seguida, por meio de dispositivos de análise semiótica (o quadrado semiótico e as modalizações) comparam-se e confrontam-se as modulações do /SABER/, do /CRER/ e do /QUERER/ nos movimentos semânticomodais desses três mecanismos psíquicos formulados por Freud. O objetivo é propor subsídios teóricos (eventualmente extensíveis à clínica) capazes de distinguir, com base nas estruturas extraídas dessas modalidades, as posições subjetivas diferenciadas do paciente. Palavras-chave: recalque, rejeição, denegação, psicanálise, semiótica.

ABSTRACT: Repression, denial, denegation: subjective modulations of the will, of belief and knowledge. This paper returns to three Freudian concepts - Verdrängung, Verwerfung and Verleugnung - , and it discusses the difficulties of their understanding because of the translations available in Portuguese based on a semantic analysis of the original in the German version. Then, through some devices of semiotic analysis (the semiotic square and its modalizations), the modulations of /KNOW/ /BELIEVE/ /WANT/ are compared and confronted in the semantic-modal movements of these three psychic mechanisms formulated by Freud. Our goal is to propose theoretical explanations (possibly applying them to the clinic) able to distinguish, based on the extracted structures of those modalities, the different subjective positions of the patient.

Keywords: repression, repudiation, denial, psychoanalysis, semiotics.

\footnotetext{
*Esta pesquisa recebe fomento do CNPq pela bolsa-produtividade para Waldir Beividas.
} 


\section{INTRODUÇÃO}

Dentre as várias interpretações plausíveis da obra freudiana, uma delas entende que a linguagem adotada pelo vienense para suas proposições sobre os mecanismos inconscientes foi, via de regra, buscada no linguajar corriqueiro de sua época. Não teria havido grande preocupação em amarrar definições restritas ou delimitações conceptuais severas, inventar neologismos, criar conceitos em lógica rigorosa e impecável. Tal entendimento encontra lastro: "a essa questão de delimitação de conceitos não lhe temos dedicado ainda em psicanálise atenção suficiente", escreve Freud num texto já bem tardio em sua imensa obra (FREUD, 1932/1973, vol. III, p.3137).

Se isso puder soar como 'fragilidade' a adeptos implacáveis de implacável cientificidade, se os textos freudianos lhes parecem mais literatura de imaginação fecunda do que demonstração em lógica estrita, convoquemos em favor do psicanalista uma frase feliz de seu carismático seguidor, Lacan. Ao encontrar no seu mestre suficientes pistas para amarrar vez por todas o inconsciente à linguagem, propôs vê-lo estruturado como linguagem, materna, cotidiana, do homem comum; propôs levar a própria psicanálise à tarefa de engajar-se nos estudos sobre a linguagem, ele próprio na dianteira, convocando a linguística de seu tempo:

\footnotetext{
"E se reconheço que o inconsciente não pode de forma alguma ser abordado sem referência à linguística, considero que juntei meu esforço à abertura freudiana. Mas já é muito que o próprio Freud tenha aberto esse caminho, dado-lhe o eixo e a prática, mostrado que era doravante a única medicina real possível” (LACAN, 1976, p.19, grifos nossos)
}

De fato, já é muito que Freud tenha rastreado com o fino radar da sua sensibilidade a farta fenomenologia do que ocorre no inconsciente. E, se ele próprio reconhece e parece ressentir-se da atenção insuficiente sobre a delimitação dos conceitos, também isto se deve ver como outra pista deixada aos seus seguidores. É o que pensamos dever ser uma saga incessante no campo da psicanálise: a contínua tarefa de conceptualização e de sua atualização.

Nessa tarefa, perante as tentativas já levadas a termo até hoje, ainda não é de nosso conhecimento a que vamos proceder aqui: delimitar certos movimentos semânticos de alguns conceitos freudianos acionando dispositivos de análise oriundos da teoria semiótica de matriz europeia, derivada da linguística de Saussure e promovida por A. J. Greimas e seus seguidores.

Dentre tantas expressões destinadas a virarem conceitos, selecionamos para a discussão a Verdrängung, a Verwerfung e a Verleugnung, por sua importância no campo psicanalítico - é bem conhecida a ligação forte entre tais termos e as estruturas psíquicas basais: neurose, psicose e perversão —, e também pela confusa com- 
preensão dos mesmos a que levam as traduções disponíveis em português. Para ilustrar um pouco a confusão, utiliza-se nas edições brasileiras como tradução tanto de Verleugnung quanto de Verwerfung o mesmo vocábulo: “rejeição”. A partir disto, nos deparamos com algumas questões: o que Freud queria fazer-nos entender dos mecanismos inconscientes subjacentes a essas expressões distintas? Quais os significados deles para a língua alemã corrente dos seus dias, visto que foi nesse registro de linguagem cotidiana que foi buscá-los?

Assim sendo, temos como tarefa aqui um estudo mais detido destas exclusões (Verdrängung, a Verwerfung e Verleugnung), abordando seus conteúdos nocionais dicionarizados em língua natural com a colaboração da confrontação e da comparação de estruturas modais da semiótica, pois acreditamos que estes conceitos partilham semelhanças e diferenças, que nos compete averiguar, enquanto estruturas de linguagem ou de discurso. Esperamos que esta releitura e discussão crítica levem a uma revitalização e re-atualização dos conceitos psicanalíticos, tarefa sempre necessária em toda disciplina, o que, segundo acreditamos, beneficiaria as definições destes na psicanálise com possíveis e eventuais reflexos na escuta do psicanalista.

\section{A VERDRÄNGUNG}

Quando buscamos no dicionário Grosswörterbuch Deutsch als Fremdsprache o significado do verbo do qual Verdrängung é derivado (verdrängen), encontramos:

“1. alguém recalca alguém/algo (de/de algo), alguém ocupa o lugar de alguém <alguém da sua posição, do seu lugar>, 2. algo recalca algo (de/de algo), algo ocupa gradualmente o lugar ou função de algo: os grandes veleiros foram recalcados por navios a vapor, 3. deixar algo desagradável psíquico desaparecer de sua consciência: ela recalcou (a lembrança) a vivência terrível.” (2003, p.1041).

Nesta última definição há uma limitação: em razão de o dicionário ser atual, é possível que se encontre já impregnado por acepções psicanalíticas. É bastante provável que tenha origem em Freud, e antes dele não fosse encontrada no idioma alemão coloquial. De qualquer forma, detenhamo-nos na última definição encontrada no dicionário: “deixar algo desagradável psíquico desaparecer de sua consciência”.

Nesta definição, sublinhamos dois verbos: “deixar" e "desaparecer”. O primeiro incide na posição do sujeito, e o segundo, na do objeto. "Deixar" quer dizer: "Permitir ou possibilitar que alguém faça algo" (p.634). "Permitir" significa "Concordar que alguém deva fazer algo" (p.311); "possibilitar” é "tornar possível”, e "possível” é "Poder existir” (p.702). Por sua vez, “desaparecer” significa: "1. Ir embora, e não estar mais para se ver (...) 3. Algo parar de existir” 
(p.1.123). Salientemos que antes de o objeto da frase "desaparecer", ele é visto como "desagradável”: “1. Difícil ou desfavorável para alguém (...), 4. Algo doloroso para alguém” (p.1.065).

Na definição de Verdrängung, então, encontramos na posição do sujeito os verbos modais: FAZER com que POSSA/DEVA EXISTIR/FAZER a desaparição do objeto, ou seja, o NÃO-SER objetal para se ver/encontrar. O sujeito, portanto, permite, possibilita, que algo desagradável, doloroso, NÃO-ESTEJA encontrável à consciência. Há uma atividade do sujeito, que determina o que PODE/DEVE acontecer a este conteúdo, ou qual PODE/DEVE ser seu estado.

Com a posse da definição alemã do termo, podemos pensar em sua tradução psicanalítica para a língua portuguesa: recalque ou repressão. Hoje em dia, a tradução mais utilizada no meio psicanalítico é recalque, provavelmente pela influência francesa que a psicanálise brasileira sofre (na tradução de Laplanche das Obras de Freud, o termo utilizado é refoulement, melhor traduzido por recalcamento). No entanto, na atual tradução brasileira das Obras Completas, como também nas traduções inglesa e espanhola, o termo ainda utilizado é repressão.

O termo repressão remete-nos ao ato de reprimir(-se), que significa:

“1. Sustar a ação ou movimento de; conter, reter, moderar, coibir, refrear, represar (...) 2. Não manifestar, ocultar, disfarçar, dissimular (...) 3. Violentar, oprimir, vexar, tiranizar (...) 4. Impedir pela ameaça ou pelo castigo, proibir (...) 5. Castigar, punir (...) 6. Conter-se, moderar-se, dominar-se, refrear-se” (FERREIRA, 1986, p.1490)

Percebemos aí várias semelhanças com o conteúdo original do termo. No entanto, seu significado não é de todo igual. O que há de semelhante é o sentido de contenção, de impedimento, de algo cuja manifestação não se quer. Já no termo recalque, no qual há o ato de recalcar, temos como significação: “1. Calcar outra vez; repisar (...) 2. Insistir em (...) 3. Impedir a expansão de; conter, reprimir, refrear" (idem, p.459). Para definirmos este termo, portanto, temos que saber previamente o que é "calcar":

“1. Pisar com os pés (...) 2. Machucar com força, comprimir (...) 3. Fig. : Oprimir, humilhar, vexar (...) 4. Reprimir, conter (...) 5 Não dar importância a, desprezar (...) 6. Decalcar (...) 7. Machucar com força; comprimir (...)” (FERREIRA, 1986, p.318)

Nesta tradução, apesar de nela estar inclusa a palavra "reprimir", encontramos um limite que nos obriga a pensar: a palavra alemã não tem, em nenhum ponto, uma semântica que leve a pensar que algo aconteceu anteriormente para depois se "fazer de novo". 
Desta forma, não se tem qualquer barreira ao utilizar "repressão" — podemos utilizar o termo em qualquer trecho escrito por Freud. No entanto, não é o que ocorre com o outro. Se utilizarmos "recalque”, não poderíamos dizer "recalque original", pois o significado da palavra impõe necessariamente que antes do recalcamento haja um calcamento, ou calcadura (com isso, o "original" seria o calcamento).

Apesar deste obstáculo à tradução do termo por "recalque”, ganhamos uma definição mais rica e mais apropriada ao que Freud quer nos fazer entender por "Verdrängung", uma vez que este mecanismo ocorre em duas etapas: o "recalque" (com as ressalvas acima) original e o recalque propriamente dito. Além disto, sabemos que a palavra remete à "repressão", o que nos beneficiaria, já que em apenas uma palavra teríamos a ideia da repressão e das fases. Por causa dos ganhos com a tradução por recalque, aqui utilizamos esta tradução como a mais apropriada.

\subsection{Verdrängung em Freud e a sua modalização semiótica}

Para acionarmos uma análise de perfil semiótico sobre o que mais abaixo ficará explicitado como uma "modalização semiótica" do recalque, retomemos previamente um evento fundamental para o recalque: a constatação da diferença anatômica entre os sexos. Somente após tal constatação é que há a inclusão do sujeito em uma lei, o que possibilita o recalque.

\subsubsection{A diferença anatômica entre os sexos e seus efeitos}

Conhecimento clássico em psicanálise freudiana, a constatação da diferença anatômica entre os sexos se dá a partir do complexo de castração. Inicialmente, a criança pensa que não há distinção, e apenas a partir das ameaças reais ou fantasísticas que sofre passa a se interessar pelo assunto. Aí se dá a manipulação, ou seja, uma ação intersubjetiva em que um sujeito, por intimidação, transmite um determinado saber, tendo em vista que tem o “poder" para tal.

Primeiramente, acredita que um dia o pênis das meninas vai crescer, mas, depois, ao constatar que sua mãe também não o tem, a ameaça de castração passa a fazer sentido. Assim, aqui se dá uma passagem da interpretação do sujeito de que a castração é mentira (que PARECE, mas NÃO É) para a de que é verdadeira (PARECE e É). Então, finalmente, acredita-se (CRER SER) nela, e se aceita o saber. Em um quadrado semiótico (GREIMAS, 1970, 1979), poderíamos montar o processo da crença na diferença anatômica entre os sexos da seguinte maneira [atentar para a direção das setas]: 


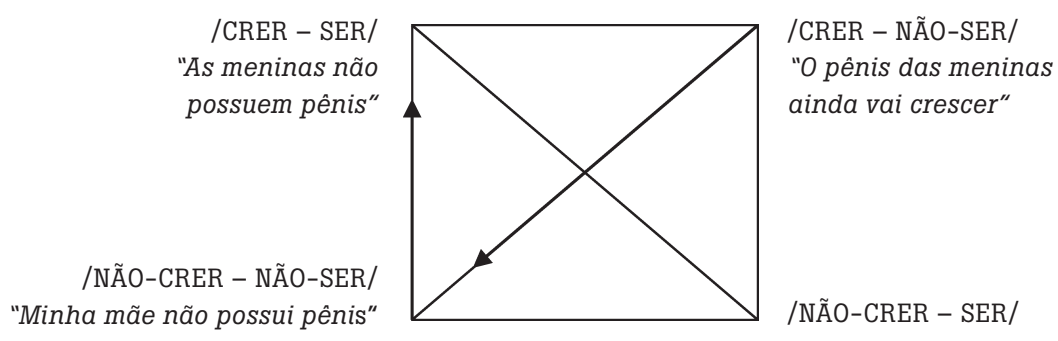

No entanto, o efeito da crença parece atrelado à volição do sujeito por esse saber. Inicialmente, recusa-o, por acreditar ser falso, e apenas com a constatação da diferença é que passa à aceitação deste saber. Isso pode ser ilustrado acionando o quadrado semiótico das modalidades volitivas:

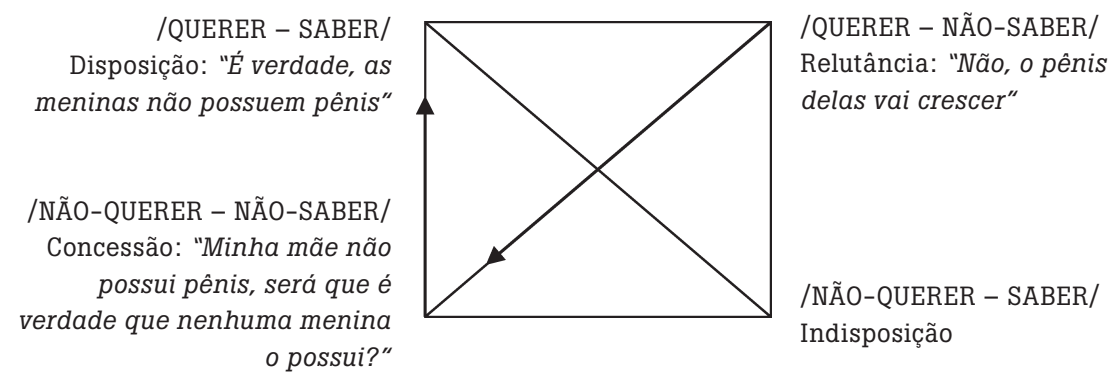

O reconhecimento da diferença traz uma série de efeitos. Dentre eles, o principal é que o menino reconhece o pai enquanto lei e entende a interdição do incesto, respeitando-a. Isto evita que a ameaça se torne real e que, com isto, seu pênis lhe seja retirado. Desta forma, há “a crise terminal do Édipo, vindo interditar à criança o objeto materno” (LAPLANCHE \& PONTALIS, 1998, p.74), ou seja, acontece o recalque do Complexo de Édipo. Já com as meninas ocorre o contrário: elas passam a invejar o pênis. Assim, odeiam a mãe por não terlhes dado o pênis, e se aproximam do pai, na esperança de que este lhes dê o órgão masculino. Essa aproximação culmina na entrada no Complexo de Édipo. Posteriormente, substitui-se o desejo de ganhar o pênis pelo desejo de ter um filho do pai.

Desta maneira, o que se recalca é o Complexo de Édipo. Recalca-se porque se entende que há uma lei de interdição de incesto, que passa a operar graças ao reconhecimento da diferença anatômica entre os sexos. Então, quando pensamos na diferença anatômica entre os sexos, há uma aceitação deste saber, devido ao medo de uma efetivação de ameaças. O que é recalcado é a representação interna, ou seja, o desejo do filho pela mãe e o da filha pelo pai. 


\subsubsection{0 recalque de um conteúdo psíquico}

Neste momento, tomamos como base para nossa análise casos em que Freud e/ ou Breuer explicitavam o mecanismo do recalque.

A primeira asserção que podemos trabalhar é com a hipótese de que o recalque é mantido e ocasionado por um ato intencional, logo, de volição, o que nos permite afirmar que o /QUERER/ modaliza o discurso. No decorrer da obra de Freud, nos deparamos com vários exemplos de pacientes que falavam sobre esse "querer", tal como no caso de Anna O., em que Breuer, esclarecendo a razão de sua paciente ter emudecido, salienta que: "ela foi muito ofendida e decidiu não falar nada sobre isso." (BREUER \& FREUD, 1895/1973, p.23, grifo nosso). Aqui, a paciente perde a capacidade de falar após suprimir uma declaração.

No recalque, o “saber” também entra em jogo, já que há um desconhecimento (/não-saber/) de determinado conteúdo. Freud, ao relatar o caso de sua paciente Frau Emmy von N., declara uma situação em que a questiona sobre a origem de sua gagueira e se depara com a ausência de respostas. O analista interroga: "A senhora não sabe isso? - Não. - Sim, por que não? — Por quê? Porque eu devo não [saber]” (BREUER \& FREUD, 1895/1973, p.51, grifo nosso). Atentemos não apenas para o discurso modalizado pelo /NÃO-SABER/, mas também para o surgimento de um /DEVER/ da paciente diante do conhecimento.

No entanto, o caso que consideramos explicitar melhor como o mecanismo do recalque é modalizado pelo /QUERER-SABER/ é o da governanta inglesa Miss Lucy. No decorrer da análise, é suposto que a paciente ama o patrão. Contudo, ela se omite quanto a esta ideia de Freud. Quando esta suposição é confirmada por relatos da própria governanta, o analista questiona a razão de não ter dito antes, e ela relata: "eu não sabia disso, ou melhor, eu não queria saber, queria tirar da minha cabeça, nunca mais pensar nisso" (BREUER \& FREUD, 1895/1973, p.94, grifos nossos). Há, portanto, uma ideia incompatível, que é recalcada pelo Eu. Assim, há o recalque, e as pacientes querem não mais saber sobre o evento recalcado, o que é demonstrado a partir de seus discursos na situação de análise. Logo, inicialmente o discurso das pacientes parece ser modalizado por um /QUERER - NÃO-SABER/ (não importa aqui que no discurso manifestado, a coisa se expresse sintaticamente na forma "não querer saber". A expressão "tirar da cabeça” figura bem isso: um /QUERER/ - NÃO (mais)-SABER/).

O querer dinamiza a cadeia, a um passo em que o saber é dirigido. O sujeito tem que escolher o que faz com um saber, se aceita ou não que este permaneça em sua consciência. Em todos os casos apresentados por Freud, se passa de um conhecimento, mesmo que momentâneo, de determinado conteúdo intolerável para, em seguida, devido ao recalque desse saber, passar 
progressivamente (já que inicialmente há uma dúvida) a um desconhecimento. Assim, Dora recalca o amor pelo pai, Miss Lucy, uma paixão pelo patrão, e Fräulein Elisabeth, a vontade de casar com o marido de sua falecida irmã, dentre outros. No entanto, o saber está lá, mesmo que apenas inconscientemente. Desta forma, após o recalque, há um sujeito modalizado pelo /CRER - NÃO-SABER/, que assim é articulado:

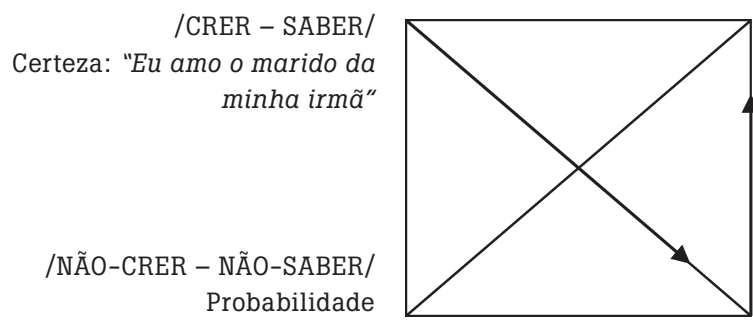

/CRER - NÃO-SABER/
Improbabilidade: "Não, eu não o amo"

/NÃO-CRER - SABER/

Dúvida: "Não, eu não sei mais se o amo, pois não devo. Tenho que esquecer esta ideia"

Assim, quando o paciente é questionado sobre o conteúdo recalcado, ele quer não saber deste, quer manter o seu esquecimento, possuindo uma postura ativa nesse processo. Há um desejo de /QUERER - NÃO-SABER/, e não propriamente um /NÃO-QUERER - SABER/. Esta vontade faz com que o conteúdo intolerável se mantenha ausente da consciência, o que traz o efeito de uma crença, ilusória, da não existência de tal conteúdo (/CRER - NÃOSER/). Após o recalque acontecer, o paciente crê não mais saber o que ocorreu, ou seja, é modalizado por um /CRER - NÃO-SABER/. Assim, ele sabia e não mais sabe. Há a passagem de um saber anterior para um esquecimento (ativo). $\mathrm{E}$, no entanto, sabe-se, por mais que apenas inconscientemente. Ao irromper este conteúdo inconsciente em sua consciência, temendo a deparação com o intolerável, o paciente nega-o, dizendo “não”, “não sei nada disso”, enfim, quer aquilo longe de sua consciência.

Em análise, o paciente se depara com o caminho inverso ao do mecanismo do recalque. O que é proposto é que ele saia do desconhecimento do conteúdo intolerável para elaborar seu conhecimento. Isto é possível apenas porque a postura do paciente diante deste saber toma um estatuto diferenciado: ele deixa de relutar (/QUERER - NÃO-SABER/) para conceder (/NÃO-QUERER - NÃO-SABER/) que este saber venha à consciência. Com esta concessão, o sujeito deixa de ser modulado por /CRER - NÃO-SABER/ e passa a /CRER - SABER/. 


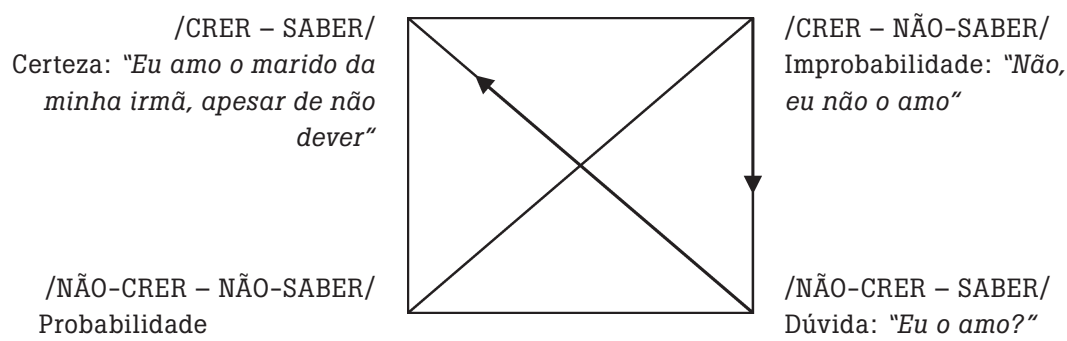

Diante disto, o que a psicanálise se propõe a fazer é mostrar, a partir do discurso do próprio paciente, que esta crença é ilusória, pois o saber permanece, por mais que inconsciente, e dá provas de sua existência reiteradamente, através de sonhos, sintomas, atos falhos, etc.

\section{A VERWERFUNG}

Diante da Verwerfung deparamos com um mecanismo de exclusão que Freud citou com maior ênfase em “O Homem dos Lobos” (FREUD, 1918[1914]/1982). A tradução hoje utilizada nas Edições Standard Brasileira das Obras Completas é a de "rejeição", a mesma utilizada para Verleugnung. Em inglês, encontramos repudiation ou foreclosure, e em espanhol, repudio.

Lacan propôs a tradução do termo por forclusion, ao procurar algum termo que equivalesse mais ajustadamente ao que Freud concebia por Verwerfung. No Brasil, fazemos um aportuguesamento deste por "forclusão”, ou "foraclusão”. No entanto, forclusion equivale a "prescrição" em português. Prescrição é uma palavra que juridicamente significa:

"5. Jur. Perda da ação atribuída a um direito, que fica assim juridicamente desprotegido, em consequência do não uso dela durante determinado tempo (...) 6. Jur. A maneira pela qual se extingue a punibilidade do autor de um crime ou contravenção, por não haver o Estado exercido contra ele no tempo legal o seu direito de ação, ou por não ter efetivado a condenação que lhe impôs.” (FERREIRA, 1986, p.1387)

Diante do significado do termo, fica-nos o questionamento de qual a relação desta palavra com a utilizada por Freud. Etimologicamente, o verbo do qual de onde Verwerfung se origina significa "Não aceitar algo, porque se acha ruim. < um pensamento, um plano, uma proposta>” (LANGENSCHEIDT, 2003, p.1133). Devido a esta grande diferença, entendemos que a tradução lacaniana é sugerida pelo que o psicanalista francês teoriza em sua releitura freudiana, e não por uma preocupação em dar uma tradução literal ao termo. 
Como o nosso objetivo é discutir sobre a melhor tradução, apesar de entender que não há uma perfeita, que contemple perfeitamente o que Freud teoriza, desejamos não interferir tanto nas palavras utilizadas por ele. Assim, buscamos um entendimento dos termos utilizados por outros idiomas, tais como: rejeição e repúdio.

“Rejeição” é: “Ato ou efeito de rejeitar” (FERREIRA, 1986, p.1478), e rejeitar significa:

“1. Lançar fora, largar, depor (...) 2. Lançar de si; tirar de si; repelir (...) 3. Lançar de si; expelir; vomitar, regurgitar (...) 4. Não admitir, recusar (...) 5. Não aprovar; reprovar, desaprovar (...) 6. Ter em pouca ou nenhuma conta; desprezar, desdenhar (...) 7. Defender-se de, repelir (...) 8. Opor-se ou negar-se a (...) 9. Atirar, arremessar, lançar, arrojar (...) 10. Repelir, afastar, $\operatorname{apartar}(. .) ”.($ idem)

"Repúdio" é o "Ato ou efeito de repudiar” (p.1491), e repudiar: "1. Rejeitar (a esposa) legalmente; divorciar-se de (a mulher) 2. Rejeitar, repelir, recusar (...) 3. Abandonar, desamparar." (idem). Das duas, a tradução que nos parece mais adequada é "rejeição", pois engloba a não-aceitação, ou seja, a oposição pelo sujeito de algo ruim, o que está presente na palavra alemã.

\subsection{Verwerfung em Freud e sua modalização semiótica}

Primeiramente, para entendermos como se dá a rejeição, temos que nos remeter ao caso "O Homem dos Lobos", relatado em Aus der Geschichte einer infantiler Neurose [>Der Wolfsmann<] (História de uma Neurose Infantil) (FREUD, 1918[1914]/1982). Neste caso, observamos exemplos que salientam a ameaça de castração que a criança sofre, como quando brinca com o pênis na frente da babá e ela o recrimina, afirmando que se fizesse aquilo, ficaria uma ferida no lugar. No entanto, o menino não quer saber nada sobre esta ameaça, e recalca as hipóteses remetidas a ela. A criança passa a procurar provas de que ela é mentirosa, mas logo percebe que as meninas possuem um órgão diferente do dos meninos. Assim, é como se ele saísse das seguintes hipóteses:

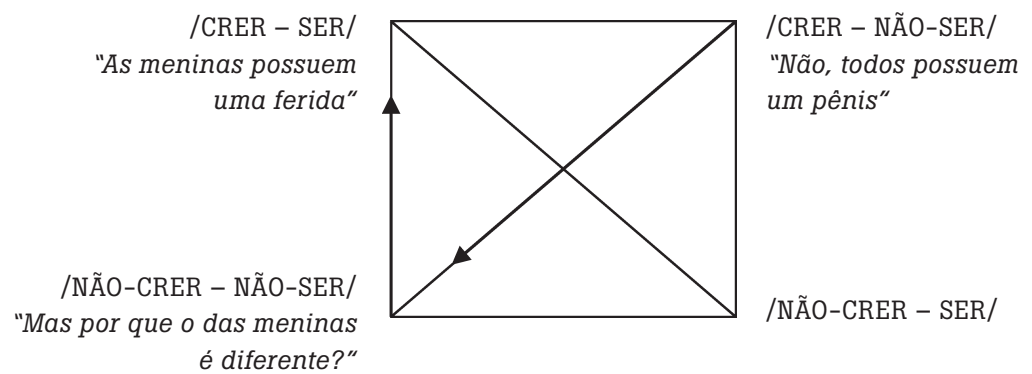


Contudo, quando chega à ideia de que as meninas possuem uma ferida, repele-a, não querendo saber mais nada neste sentido, buscando inclusive novas explicações para, por exemplo, a diferença sexual (as meninas possuem um “traseiro frontal”), e para o ato sexual (que se dá pelo ânus), explicações estas que substituem a realidade da castração. Tudo isto porque, se aceitar a castração, seu pênis lhe é tirado.

Para manter essa hipótese da indiferença sexual, o homem dos lobos recalca a ideia de que as meninas possuem uma "ferida", pois isto o ameaça, isto é, confirma a ameaça feita pela babá. Então, com o recalque, é como se o homem dos lobos voltasse ao ponto de partida, e permanecesse com a ideia de que não há diferença sexual.

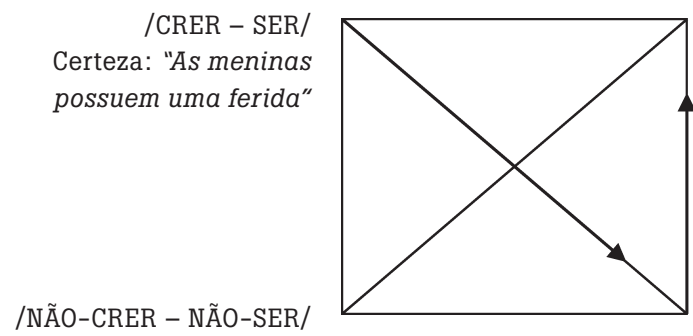

\author{
/CRER - NÃO-SER/ \\ Improbabilidade: "Não, \\ elas possuem um traseiro \\ frontal \\ /NÃO-CRER - SER/ \\ Dúvida: "Se elas possuem \\ uma ferida, então corro o \\ risco de que arranquem meu \\ pênis. Eu não posso acreditar \\ nisto. Deve haver outra \\ explicação"
}

Então, passa a acreditar não saber nada no sentido do recalque, pois não há castração e as provas disso são as conclusões a que chega sobre a diferença sexual e sobre o ato sexual: o ato se realiza a tergo e as meninas possuem um traseiro frontal, não uma "ferida”. Assim, quando lembra de seu medo de vespa (Wespe), e em vez de usar esta palavra fala Espe, ele parece ser modalizado pelo /CRER-SABER/ da diferença anatômica, ou seja, que as meninas não possuem o pênis, e, sim, uma ferida (a vespa não teria o W e suas asas lhe teriam sido arrancadas). Aproximar-se da vespa representa entrar em contato com o conteúdo recalcado que tanto o apavora. A mesma coisa acontece quando adoece por contrair gonorreia, reavivando a ideia de que as meninas possuem uma ferida no lugar do pênis, e que ele pode vir a ter esta ferida. Outro exemplo, oferecido por Freud, que pode ilustrar esta modalização é quando discute sobre uma alucinação que o paciente tem, em que imagina que seu dedo havia sido arrancado. Ao se acalmar, o homem dos lobos vê que seu dedo ainda está lá, ileso. Então, passa a acreditar que os pênis das mulheres são arrancados ao nascer, mas ao mesmo tempo afasta essa ideia pelo recalque. 
Portanto, ao pensarmos na rejeição como Freud nos conceitua, "não querer saber nada no sentido do recalque”, pensamos, novamente, no sujeito modalizado por um /QUERER - NÃO- SABER/, e seu efeito é a descrença na diferença anatômica entre os sexos. O que acontece nesta confrontação é que o sujeito rejeita determinado saber (/QUER-NÃO-SABER/), pois se o aceitar o seu pênis é cortado. No caso da rejeição, não se quer acreditar que há a castração.

Apesar de a modalização da rejeição ser aparentemente igual a do recalque, salientemos que, na primeira, o sujeito é modalizado por um /QUERER - NÃOSABER/ da diferença anatômica entre os sexos, ou seja, de uma realidade visual. Na segunda, não se trata disto, o sujeito deseja que um conteúdo interno permaneça inconsciente.

\section{A VERLEUGNUNG}

Etimologicamente, Verleugnung significa "Afirmar que não se tem ou não se conhece algo/alguém <um amigo, seu modo de pensar, seu Deus, seus ideais>” (LANGENSCHEIDT, 2003, p.1114). Como já dito anteriormente, a tradução brasileira nas Obras completas do pai da psicanálise para esse termo é a de rejeição. Em outros lugares, podemos encontrar também "recusa" ou "denegação". A tradução francesa utiliza déni; em inglês encontramos disavowal ou denial, e em espanhol renegación.

Neste trabalho, já concluímos que a tradução "rejeição” é bastante apropriada para "Verwerfung", e para evitar com que haja mais confusões, no sentido de má compreensão do texto, nos deteremos apenas nas outras opções encontradas: recusa, denegação, desmentido e renegação. "Recusa” é o ato de recusar, e recusar:

“1. Não aceitar (coisa oferecida); rejeitar (...) 2. Não se prestar, opor-se, negar-se a 3. Não aceitar, não admitir (...) 4. Não permitir; não conceder; negar (...) 5. Não se prestar, negar-se, opor-se (...) 6. Declarar-se incompetente (...) 7. Não obedecer; desobedecer (...).” (FERREIRA, 1986, p.1466)

Aqui, percebemos a semelhança entre "recusa” e "rejeição”. Já “denegação”, assim como "renegação”, é o ato de denegar, ou de desmentir. “Denegar” é:

“1. Dizer que não é verdade; negar (...) 2. Não dar, recusar, negar (...) 3. Desatender, indeferir (...) 4. Abjurar, renegar (...) 5. Não aceitar, recusar (...) 6. Desmentir, contradizer (...) 7. Não conceder, recusar, negar (...) 8. Impedir, obstar (...) 9. Recusar-se, negar-se” (FERREIRA, 1986, p.535) 
“Desmentido" foi compreendido como "que foi contraditado" ou "declaração ou palavras com que se desmente” (idem, p.569). E desmentir: “1. Declarar que (alguém não diz a verdade); contradizer; contestar (...) 2. Negar (o que outrem afirmara) (...) 3. Não corresponder a; destoar de; discrepar de; desdizer. (...) 7. Contradizer-se." (idem).

Na Verleugnung, encontramos o seguinte mecanismo: sabe-se das diferenças anatômicas dos sexos, mas não se quer acreditar nisto, e o menino, para substituir esta falta da menina, cria um fetiche, para este funcionar como um pênis, um substituto por deslocamento. Há uma oscilação entre /SABER/ e /NÃO-SABER/. O fetiche vem exatamente para contradizer o saber que lhe foi passado, ou seja, para alegar o contrário. Com isto, acreditamos que é enriquecedor tratar este conceito como "denegação" ou "renegação", pois ambos tratam tanto da recusa, que é o que quer dizer "Verleugnung" ao pé da letra, quanto do saber que é contradito por meio do fetiche.

\subsection{A Verleugnung em Freud e a sua modalização semiótica}

Na denegação, sabe-se da diferença anatômica dos sexos, crê-se na diferença, ao mesmo tempo que não se quer saber dela. Por esse não querer saber, criam-se substitutos para o pênis por meio de fetiches. Ao pensarmos na denegação como um mecanismo em que o sujeito oscila entre a recusa e o reconhecimento, temos, novamente, um sujeito modalizado por /QUERER-SABER/, que representamos da seguinte forma:

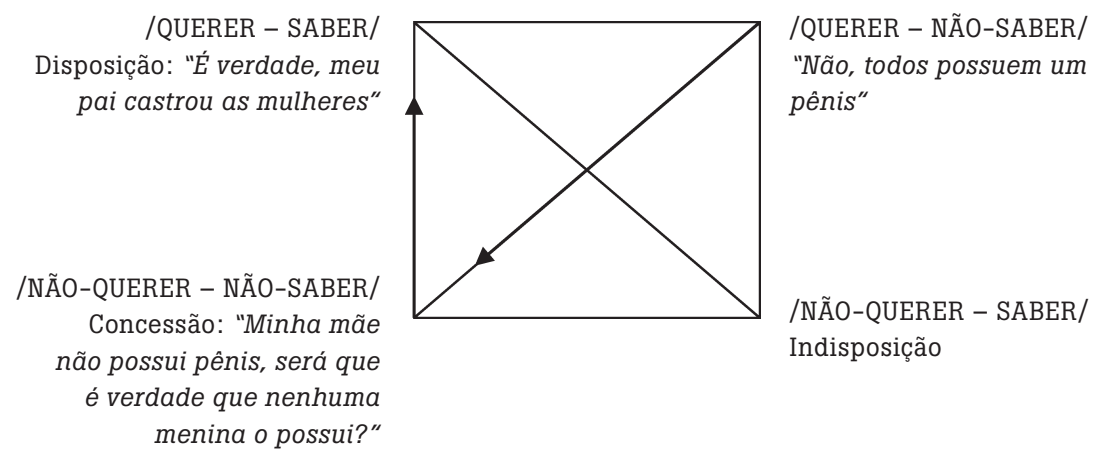

Mas, ao mesmo tempo que este processo se verifica, ocorre um retorno - o sujeito se encontra indisposto a aceitar este saber, já que sua aceitação implica em uma renúncia à satisfação pulsional. Para tanto, destrói a prova da possibilidade da castração. No retorno, o quadrado assim é formulado: 


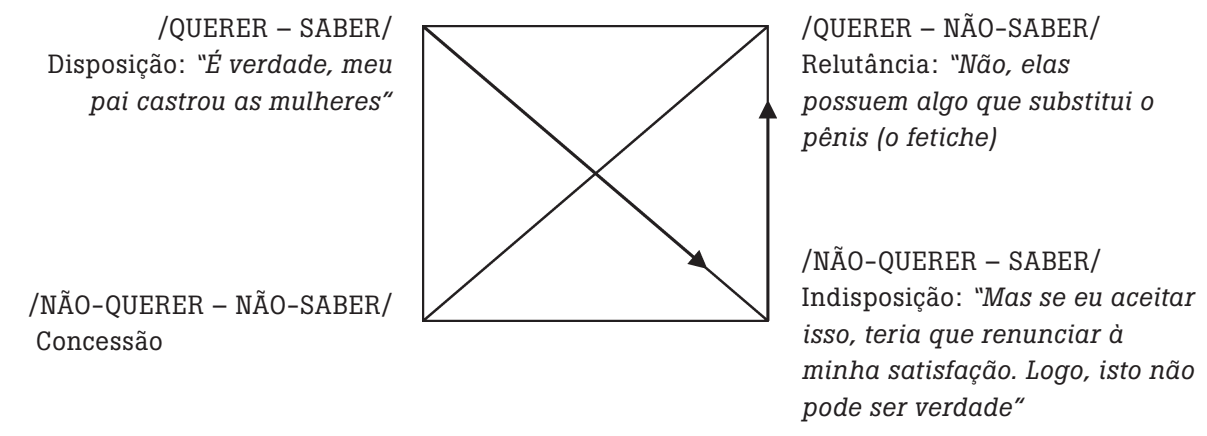

Pensamos que, na denegação, o sujeito fica predominantemente na indisposição /NÃO-QUERER - SABER/, e circula entre a disposição e a relutância a este saber o tempo todo. Encontrando-se em uma indisposição, fica na interseção entre um e outro. Como efeito desta volição temos a crença, ou não, na diferença anatômica entre os sexos, que seria representada por /CRER - SER/. Propomos então que, inicialmente, há uma passagem do desconhecimento ao conhecimento da diferença anatômica entre os sexos:

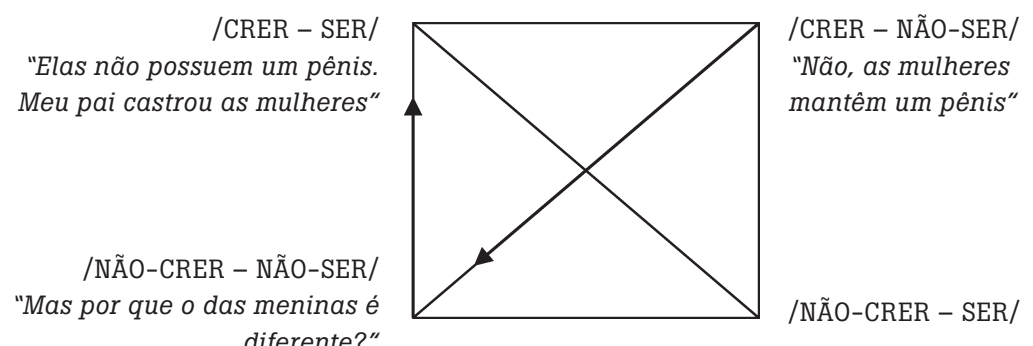

No entanto, há um retorno, pois não se aceita a diferença, o que se dá da seguinte forma:

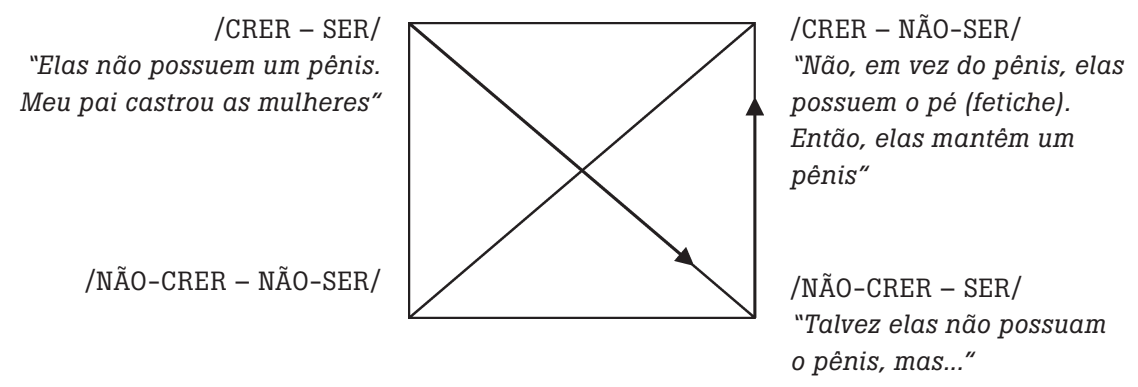

Desta forma, é como se na denegação o sujeito ficasse sempre nesta oscilação entre o /CRER - SER/ e o /CRER - NÃO-SER/, ou seja, entre a certeza da diferen- 
ça anatômica e a improbabilidade desta. Assim, aqui não há um desligamento completo da realidade, pois sabe-se da diferença anatômica entre os sexos, e, ao mesmo tempo, acredita-se no fetiche como uma prova de que o pênis ainda se mantém no corpo.

\section{A VERDRÄNGUNG, A VERWERFUNG E A VERLEUGNUNG: COMPARAÇÕES E CONFRONTAÇÕES}

Diferenciar Verdrängung, Verwerfung e Verleugnung não é tarefa tão fácil, pois nem sempre na obra de Freud tais conceitos estão delimitados e demarcados. Pelo contrário, até o momento em que começa a propô-los como conceitos psicanalíticos, ele os usa aleatoriamente, como um falante qualquer os utilizaria em língua alemã. Desta forma, com o decorrer da obra, percebe que há diferenças, sim, entre tais palavras e que estas diferenças, apesar de sutis, precisam ser salientadas. Umas foram mais bem descritas, outras menos. Cabe agora aos seguidores de sua disciplina buscar paulatinamente maior precisão e definição de tais conceitos, para que assim se possa fazer uma distinção entre eles com vistas a extrair melhor os mecanismos inconscientes em jogo.

\subsection{Comparações e confrontações}

Os três mecanismos possuem particularidades referentes ao reconhecimento da diferença anatômica entre os sexos. No recalque, o sujeito aceita a diferença, diversamente dos mecanismos da rejeição e da denegação. No entanto, há pontos em que tais conceitos se assemelham, o que pode ser evidenciado nos quadrados semióticos abaixo.

Em primeiro lugar, podemos evidenciar o quadrado semiótico do recalque, por acreditarmos que ele é a base para a compreensão dos outros dois mecanismos. Aqui, inicialmente, não se acredita que as meninas não possuam pênis. Contudo, a criança um dia constata que sua mãe também não tem, e a ameaça de castração passa a fazer sentido. Assim, começa-se a crer na probabilidade da diferença. Apenas a posteriori acredita-se (crer-ser) nela. Estas fases podem ser retomadas no seguinte esquema:

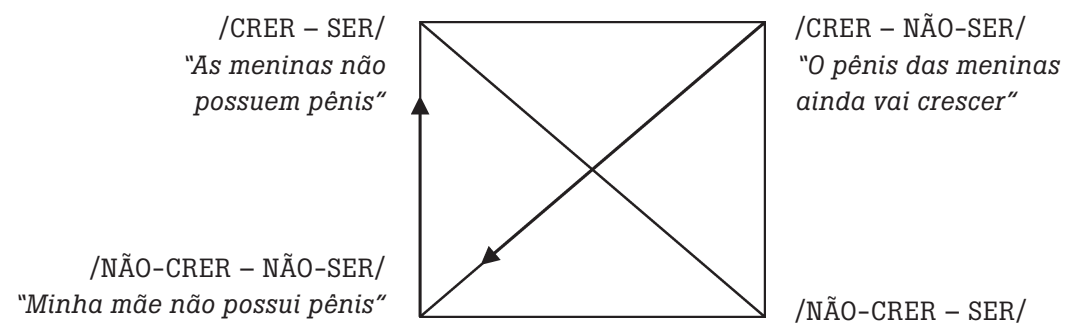


Na rejeição e na denegação, este caminho também ocorre. No entanto, após a constatação da diferença anatômica, a realidade é tão dolorosa para o sujeito que ele recusa este saber. Na rejeição, quando se chega à ideia de que as meninas possuem uma ferida, o sujeito não quer saber mais nada neste sentido. No caso "O Homem dos Lobos", observamos que o paciente acredita em uma relação sexual pelo ânus, e que as meninas possuem nádegas frontais. Tudo isto porque, se aceitar a castração, seu pênis lhe é tirado. Então, a operação ocorrida é um recalque da ideia de que as meninas "possuam uma ferida", o que ocasiona a permanência da ideia de indiferença sexual.

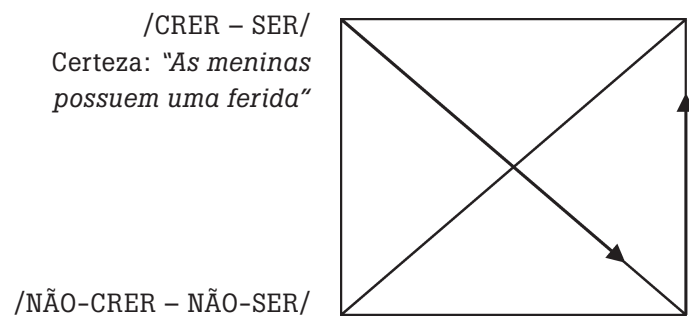
/CRER - NÃO-SER/ Improbabilidade: "Não, elas possuem um traseiro frontal
/NÃO-CRER - SER/
Dúvida: "Se elas possuem uma ferida, então corro o risco de que arranquem meu pênis. Eu não posso acreditar nisto. Deve haver outra explicação"

Já na denegação, é como se o sujeito ficasse sempre na passagem entre o /CRER - SER/ e o /CRER - NÃO-SER/, ou seja, entre a certeza da diferença anatômica e a negação desta. Com isto, aqui não há um desligamento completo da realidade, diferentemente da rejeição, pois sabe-se da diferença anatômica entre os sexos, e, ao mesmo tempo, acredita-se no fetiche como uma prova de que o pênis ainda se mantém no corpo feminino.

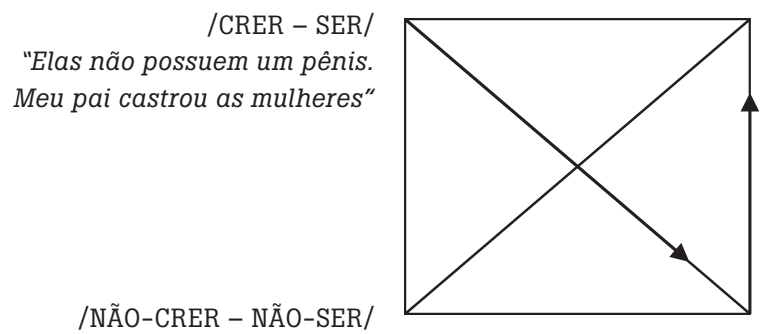

/CRER - NÃO-SER/

"Não, em vez do pênis, elas possuem o pé (fetiche). Então, elas mantêm um pênis"

/NÃO-CRER - SER/

"Talvez elas não possuam o pênis, mas..." 
Estas diferentes crenças nos três mecanismos se dão principalmente por causa do "querer" do sujeito em questão. No recalque, apesar do sujeito inicialmente querer não saber da diferença, com o tempo ele se dispõe a /QUERER-SABER/, como no seguinte quadrado:
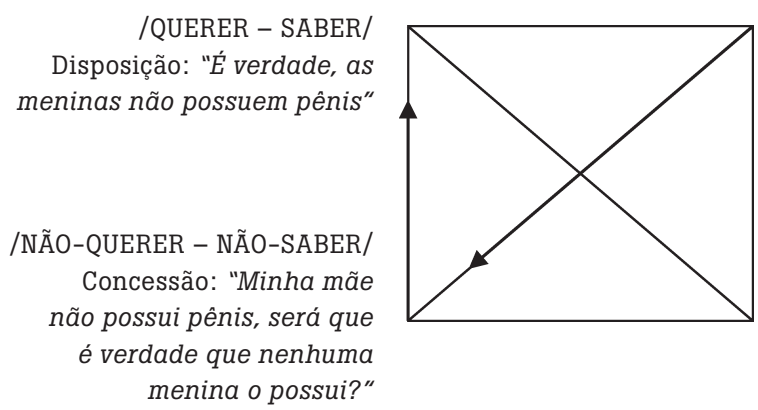

/QUERER - NÃO-SABER/ Relutância: "Não, o pênis delas vai crescer"

/NÃO-QUERER - SABER/ Indisposição

Já na rejeição, após esta "breve disposição", o sujeito recua, e novamente reluta em saber da diferença, agindo como se este conteúdo jamais tivesse alcançado sua consciência. Assim, rejeita este saber, sendo modalizado por um /QUERER - NÃO-SABER/.

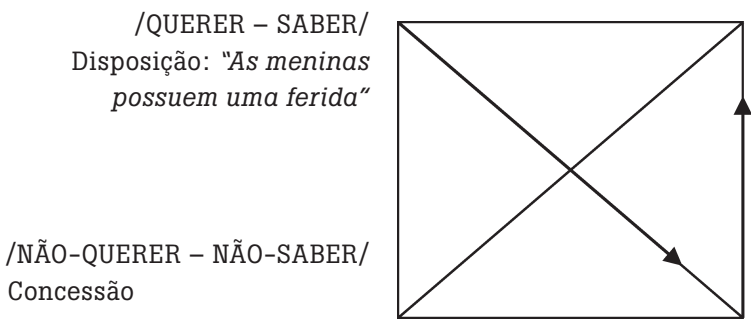
/QUERER - NÃO-SABER/
Relutância: Não, elas
possuem um traseiro frontal"
/NÃO-QUERER - SABER/
Indisposição: "Se elas possuem uma ferida, então corro o risco de que arranquem meu pênis. Eu não posso acreditar nisto. Deve haver outra explicação"

$\mathrm{Na}$ denegação, diferentemente da rejeição, o sujeito fica entre os dois polos, e se situa principalmente na modalização de /NÃO-QUERER - SABER/: 


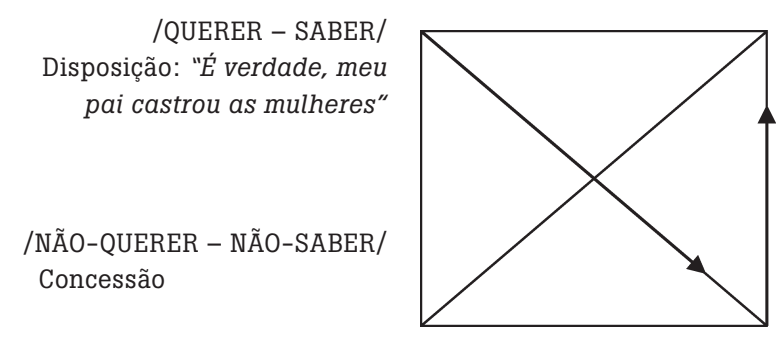

/QUERER - NÃO-SABER/

Relutância: "Não, elas

possuem algo que substitui

o pênis (o fetiche)"

/NÃO-QUERER - SABER/

Indisposição: "Mas se eu aceitar isso, teria que renunciar a minha satisfação. Logo, isto não pode ser verdade"

Assim, na denegação é como se houvesse determinada frase: "Sim, é verdade, elas não possuem pênis, mas possuem os pés, que podem ser correlatos ao pênis." Portanto, acredita-se na realidade externa, apesar de não se querer saber. Preferirse-ia que ela não existisse, mas se sabe que ela existe. Há uma contradição nesse pensamento, que é demarcado por uma negação e certa afirmação da realidade perceptiva. Assim, o rechaço se complementa com uma aceitação.

Em conclusão, contrastando os três mecanismos, eles ficam prioritariamente em polos semântico-lógicos diferentes do quadrado semiótico, o que significaria dizer que são assim representados, de acordo com a modalidade do /QUERER-SABER/:

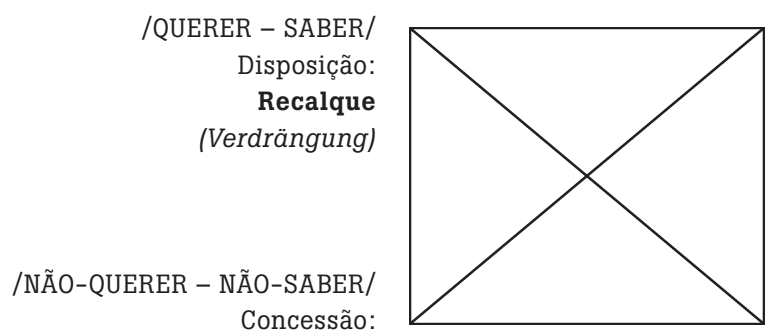

(?)
/QUERER - NÃO-SABER/

Relutância:

Rejeição

(Verwerfung)

/NÃO-QUERER - SABER/

Indisposição:

Denegação

(Verleugnung)

Os efeitos destes "quereres" se resumiriam pelas seguintes crenças da diferença anatômica entre os sexos:

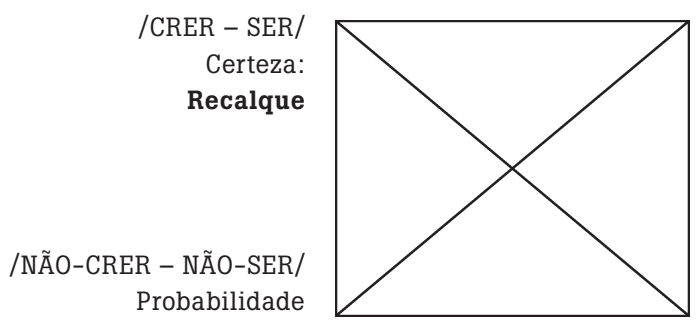

(?)
/CRER - NÃO-SER/

Improbabilidade:

Rejeição

/NÃO-CRER - SER/

Dúvida:

Denegação 
Salientemos, contudo, que estes quadrados não se dão de forma fixa ou estanque, tal como parecem ao serem apresentados nestes dois pequenos resumos das modalizações do /QUERER - SABER/ e do /CRER - SER/. Ao contrário, como verificado anteriormente, os sujeitos chegam até aí por uma construção subjetiva, ou seja, eles se movem entre os diferentes polos semânticos do quadrado, até se definir, na maior parte do tempo, em uma modalização específica.

Assim, no recalque, não há um desligamento do sujeito da realidade, enquanto na rejeição e na denegação, há. Na rejeição, há um rechaço absoluto, e na denegação há um rechaço da percepção do real, ao mesmo tempo que há certo grau de aceitação, ocasionando um registro da castração. Outra diferença que podemos apontar é que pelo recalque ser o único mecanismo em que não há um desligamento da realidade, apenas nele podemos discutir sobre recusas de pensamentos intoleráveis.

\section{BALANÇO}

Este trabalho teve como objetivo dar continuidade a estudos que estão sendo realizados por alguns pesquisadores e teóricos nos campos de interface entre as ciências da Linguagem e da Psicanálise. Aqui, nosso esforço foi de dar exemplos concretos de como a Semiótica pode apresentar algumas ferramentas lógicosemânticas e modais para eventualmente contribuir com a difícil questão que é operar com os conceitos freudianos aqui lançados sob análise. Para isto, tomamos os conceitos de Verdrängung (recalque), Verwerfung (rejeição) e Verleugnung (denegação) e, a partir das suas respectivas modalizações semióticas, propusemos uma forma outra de entendê-los. Inicialmente, propusemos uma análise de cada um separadamente, e, depois, ao perceber que eles partilhavam semelhanças modais, fomos conduzidos a confrontá-los tendo aparecido novas perspectivas ou ângulos de incidência dificilmente captáveis sem o arranjo modal.

Desta forma, mesmo que os três mecanismos possuam peculiaridades referentes ao reconhecimento da diferença anatômica entre os sexos, entendemos que existem pontos em que se assemelham, o que foi evidenciado através dos quadrados semióticos acionados na análise. Assim, concluímos que os três conceitos estão situados em diferentes polos do quadrado semiótico do /QUERERSABER/. Estes "quereres” desiguais geram diferentes crenças, o que salientamos no quadrado semiótico do /CRER-SER/.

Notemos por fim que os objetivos propostos fixaram um limite. Detivemonos apenas nos aspectos lógico-semânticos das posições subjetivas representáveis nos polos dos quadrados acionados. O mecanismo do quadrado semiótico, desde sua origem aristotélica, retomado pela teoria semiótica, apresenta apenas relações entre "contrários" (a relação horizontal entre os polos superiores e inferiores) e entre seus “contraditórios” (as relações oblíquas), prevendo ainda relações de 
“implicação" no vetor vertical. Esse mecanismo, bastante fecundo quando se tratam de fenômenos passíveis de oposições categoriais (CRER vs NÃO-CRER) não dá conta e cede a vez a outros mecanismos mais graduais que tentam recuperar o continuum dos fenômenos (crer mais e mais, ou cada vez menos... querer muito, mais ou menos, um pouco, demais...). Noutros termos, a questão da intensidade, ou antes, da tensividade (intensidade vs extensidade) que conota diferentemente os conceitos aqui em foco constitui um outro desafio que é preciso reconhecer e enfrentar, e que ficou à parte dos objetivos aqui apresentados. Sobretudo porque é mesmo a questão da intensidade com que se joga no prefixo Ver- em na língua alemã. Tudo isso indica que há uma bela partida ainda por ser jogada entre uma Semiótica Tensiva que hoje toma fôlego (ZILBERBERG, 2006) e os aspectos quantitativos (intensivos) das modulações do psiquismo, por cujas descobertas e formulações singulares, Freud para sempre será lembrado como o arguto pioneiro da alma inconsciente.

Recebido em 18/7/2008. Aprovado em 31/1/2009

\section{REFERÊNCIĀS}

ARRIVÉ, M.. (1999) Linguagem e Psicanálise, Linguística e inconsciente: Freud, Saussure, Pichon, Lacan. Rio de Janeiro: Jorge Zahar.

(2002) Linguística e psicanálise: Freud, Saussure, Hjelmslev, Lacan e outros. São Paulo: Edusp.

BEIVIDAS, W. (2000) Inconsciente et verbum: psicanálise, semiótica, ciência, estrutura. São Paulo: Humanitas/ FFLCH/ USP.

BREUER, J. \& FREUD, S. (1895/ 1973) Studien über Hysterie. Frankfurt am Main: Fischer Taschenbuch Verlag.

FERREIRA, A. B. de H. (1986) Novo Dicionário da Língua Portuguesa. Rio de Janeiro: Nova Fronteira.

FORRESTER, J. (1983) A linguagem e as origens da psicanálise. Rio de Janeiro: Imago.

FREUD, S. (1973), Obras completas, $3^{\mathrm{a}}$ ed., 3 v., Madrid: Biblioteca Nueva.

(1982). Studienausgabe. Frankfurt am Main: Fischer Taschenbuch Verlag.

(1918 [1914]). "Aus der Geschichte einer infantiler Neurose [> Der Wolfsmann<]”, Band VIII, p. 125-234.

Grosswörterbuch Deutsch als Fremdsprache. (2003) Berlin und München: Langenscheidt KG 
GREIMAS, A. J. (1970) Du sens. Essais sémiotiques. Paris: Seuil. et COURTÉS, J.(1979) Dicionário de semiótica. São Paulo: Cultrix.

LACAN, J. (1976) Conférences et entretiens dans des universités nordaméricaines. Scilicet 6/7, p. 5-63. Paris: Seuil.

Langenscheidt Taschenwörterbuch: der portugiesischen und der deutschen Sprache (1982) Berlin und München: Langenscheidt KG.

LAPLANCHE \& PONTALIS (1998) Vocabulário de Psicanálise. São Paulo: Martins Fontes.

ZILBERBERG, Cl. (2006) Eléments de grammaire tensive. Limoges: Pulim

\author{
Lina Schlachter \\ linaschlachter@yahoo.com \\ Waldir Beividas \\ waldirbeividas@gmail.com
}

